\title{
ERÄÄN AKATEEMIKON PERINTÖ
}

Vankiluku olisi sitä paitsi jonkin verran pienempi, jos itseään liberaaliksi (ja jopa ihmisoikeusaktivistiksi) kutsuva korkein virkamiesjohto käyttäisi vangin vapautumisajankohtaa koskevaa tulkinta- ja harkintavaltaansa liberaalilla eikä repressiivisellä tavalla. Herättää myös ihmetystä, että Suomen vankiloissa henkilökunnalla on vieläkin aseet, vaikka niistä on luovuttu jo kauan sitten muissa Pohjoismaissa ja monessa muussakin Länsi-Euroopan maissa.

Mitä tehdä? Ylivoimaisesti tärkein tavoite on vankiluvun alentaminen, vankilakoneiston edes osittainen purkaminen, kuten Mathiesen ehdottaa. Hänestä vapautuvat määrärahat pitäisi kanavoida valtavaan tiedotuskampanjaan, jonka tarkoituksena olisi osoittaa, että vankila ei palvele mitään järkeviä päämääriä. Lisäksi kriminaalipolitiikassa pitäisi siirtyä rikollisuuden tarkasteluun yhteiskunnallisena ongelmana. Koko yhteiskunnassa perhe- ja asuntopolitiikka tulisi tehostaa, opetusta ja työoloja kehittää sekä tulonjakoa tasoittaa. Vapautuneiden vankien jälkihoitoa on laajennettava ja uhrin asemaa parannettava.

Suomessa voisi tehdä tässä ja nyt hyvin paljon. Vireillä olevan rikoslakiuudistuksen avulla vankiluvun voisi pudottaa pohjoismaiselle tasolle. Noin kolmasosa vangeista istuu turhaan laitoksessa sen takia, että he ovat sattuneet syntymään väärässä Pohjoismaassa. Viranomaiset voisivat alkaa soveltaa liberaalia vankeinhoitolainsäädäntöämme liberaalisella tavalla. Suuren yleisön ja tiedotusvälineiden pitäisi ottaa lähtökohdaksi, että vapaudenriisto on aina järkyttävä, traumaattinen kokemus, ja että vankeudella on vakavia mielenterveydellisiä ja sosiaalisia haittavaikutuksia.

Paul Van Aerschot
DUDINTSEV, VLADIMIR: Valkeat vaatteet. SN-kirjat, Helsinki, 1987.

Petroskoissa vuonna 1951 julkaistussa keskikoulun oppikirjassa Darvinismin perusteet todetaan seuraavaa (ss. 102-103): "Hankittujen tuntomerkkien ja ominaisuuksien periytyminen organismissa on elollisen luonnon laki" (korostus alkutekstissä).

Tällä virkkeellä on monta tarinaa. Yksi niistä sisältyy Vladimir Dudintsevin romaaniin Valkeat vaatteet, joka ilmestyi Neuvostoliitossa viime vuonna gorbatshovilaisen uudistuspolitiikan ilmentymänä usean vuoden hyllytyksen jälkeen.

Dudintsev kertoo tarinan sellaisten biologien kokemuksista, jotka eivät hyväksyneet ajatusta hankittujen ominaisuuksien periytymisestä. Kirjan päähenkilö Fjodor saa tehtäväkseen paljastaa maataloustieteiden akatemian alaisessa tutkimusinstituutissa toimivan vääräoppisten "koplan" mutta ajautuukin koplan jäseneksi, joutuu vähitellen epäsuosioon, tulee ilmi ja pakenee instituutista mukanaan vääräoppisilla menetelmillä jalostettu uusi perunalajike. Tutkimusinstituutin juonittelujen ja ilmiantojen kyllästämiin tapahtumiin osallistuu joukko kasvinjalostajia, joiden elämänvaiheet kuvastavat keskeisiä muunnoksia geneetikkojen kohtaloista 1940luvun lopun Neuvostoliitossa (menehtyminen keskitysleirillä, itsemurha, maastoutuminen muille tieteenaloille, julkinen katumus ja parannus, pyrkyryys...). Kirja on yksityiskohtainen ja historiallisille tapahtumille uskollinen, sujuva ja jännittävä, mutta en esittele tässä pidemmälti sen sisältöä.

Dudintsevin kuvaamat henkilöhistoriat leikkaavat toista, näiden taustalla olevaa tarinaa: Mistä väittämä hankittujen ominaisuuksien periytyvyydestä on peräisin?

Ongelma on melkoinen. Väittämä on ristiriidassa viisikymmentä vuotta aiemmin vakiintuneen perinnöllisyyden mekanismeja kos- kevan näkemyksen eli mendelismin kanssa. Sen mukaan yksilön elinaikana hankitut ilmiasun piirteet nimenomaisesti eivät vaikuta perimään, vaan hedelmöittyneen sukusolun geenistö välittyy satunnaisia mutaatioita lukunottamatta muuttumattomana edelleen. Mendelistinen perinnöllisyystiede kehittyi Venäjällä/Neuvostoliitossa 1920-luvun loppuun mennessä vahvaksi ja suurta kansainvälistä arvostusta nauttivaksi tutkimusalaksi, mutta tutkimusperinteet katkesivat jokseenkin täysin moniksi vuosiksi. Mistä on kysymys?

$$
* * *
$$

Taustaksi eräitä henkilötietoja:

DrosophILA. Pienten, pääasiassa mätäneviä kasveja ja hedelmiä ravinnokseen käyttävien kärpästen muodostama suku, jolla on ollut vuosisadan alusta saakka keskeinen merkitys perinnöllisyyden solutasoisten mekanismien tutkimuksessa. Tämä johtuu siitä, että drosofiloja on helppo kasvattaa ja risteyttää laboratoriossa, niiden sukupolvikierto on lyhyt ja niillä on sylkirauhassoluissaan ns. jättiläiskromosomeja joiden rakennetta voidaan tutkia mikroskoopilla. Drosofilat olivat myös neuvostoliittolaisten geneetikkojen keskeinen tutkimuskohde 1920-luvun alusta lähtien, kunnes ne karkotettiin laboratorioista käytännön tarpeille vieraina olioina.

Lysenko, Trofim Denisovitsh (1898-1976). Talonpoikaisen syntyperän omaava ukrainalainen kasvinjalostaja, joka kehittyi neuvostoliittolaisen maataloustutkimuksen ja perinnöllisyystieteen itsevaltiaaksi. Lysenkon uran voi periodisoida seuraavasti (selkeä ja hyvin dokumentoitu esitys sisältyy Loren R. Grahamin kirjaan Science \& Philosophy in the Soviet Union, Allen Lane, 1971): Hän aloitti työskentelynsä käytännön agronomina 1920-luvulla maatalouden koeasemilla Ukrainassa ja Azerbaidzhanissa, syrjässä varsinaisista tutkimuslaitoksista. Vuosikymmenen lopulla hän alkoi ko- 


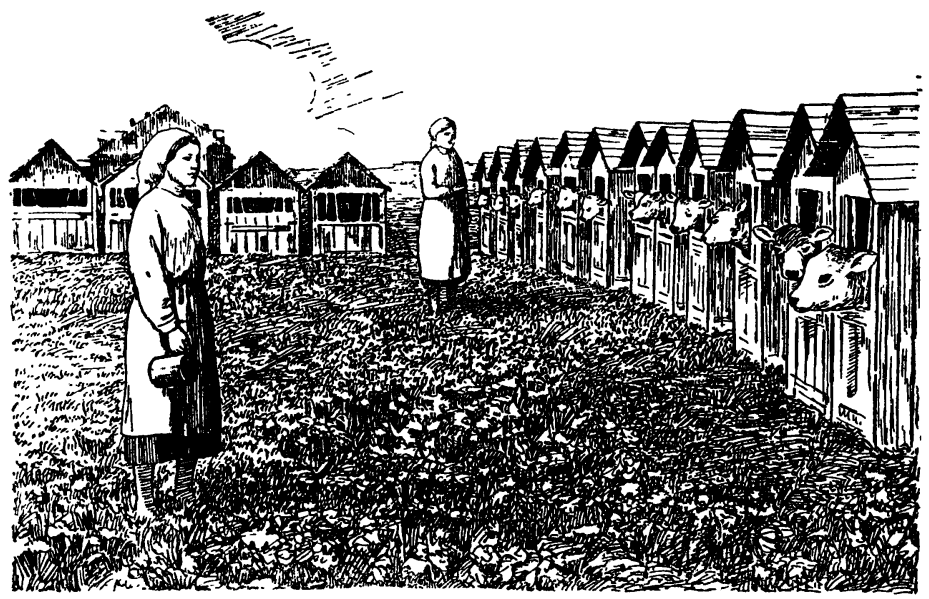

Kuva 61. Vasikat kesälaitumella „Karavajevo” neuvostotilalla.

keilla viljan siementen kylmäkäsittelyä keinona saada normaalisti syksyllä kylvettävä vilja kypsymään yhden kasvukauden kuluessa. Menetelmä oli ennestään tunnettu, mutta Lysenko kehitti kokeidensa nojalla teorian ("kasvien vaiheinen kehitys") ja lupasi siihen nojautuvasta, viljan "jarovisaatioksi" kutsumastaan menetelmästä keinon parantaa Neuvostoliiton viljantuotantoa.

Lysenkon hallinnollinen ura lähti nousuun vuodesta 1930 lähtien. Ensin hän toimi oman jarovisaatiota tutkivan laboratorionsa johtajana Odessan maatalousakatemiassa, sittemmin akateemikkona ja Neuvostoliiton leniniläisen maatalousakatemian johtajana.

Ristiriita lysenkolaisuuden ja perinteisen genetiikan välillä alkoi kyteä 30-luvun alkupuolella, mutta Lysenko liittyi siihen täydellä teholla ja teoreettisin ambitioin sekä argumentein varustautuneena aloitettuaan vuonna 1935 yhteistyönsä filosofi I.I. Prezent'in kanssa. Hän kehitti mendelismin vastapainoksi oman perinnöllisyysteoriansa, joka on kuitenkin vaikeaselkoinen ja osin sisäisesti ristiriitainen.

Perinnöllisyystieteen "kahdesta tutkimussuunnasta", kuten Lysenko niitä kutsui, järjestettiin tärkeät julkiset väittelyt vuosina 1936 ,
1939 ja 1948. Ensimmäisissä voimat olivat suunnilleen tasoissa, mutta kesällä 1948 pidetty Maataloutieteiden akatemian kokous siunasi - Stalinin tuella - Lysenkon voiton ehdoitta, ja moderni perinnöllisyystiede joutui Neuvostoliitossa maan alle.

Kritiikki Lysenkoa kohtaan nousi Neuvostoliitossa julkisuuteen heti Stalinin kuoltua, mikä johtikin melko pian geneettisen tutkimuksen uuteen käynnistymiseen. Lysenkon ura ei kuitenkaan loppunut vaikka hän joutuikin syrjään Maatalousakatemian johtajan paikalta vuonna 1956. Hän liimautui Hrushtshevin maatalouspolitiikan tieteelliseksi neuvonantajaksi - ja palasi tämän tukemana Maatalousakatemian johtoon vuonna 1961. Samassa yhteydessä muutama Lysenkon vastustaja menetti jälleen paikkansa (joskaan ei vapauttaan tai henkeään). 60luvulla tilanne kuitenkin oli jo uusi. Biologinen tutkimus oli karannut peruuttamattomasti Lysenkon käsityskyvyn ulottumattomiin, ja vuosikymmenen puolivälissä, Hrushtshevin tuen hälvettyä, Lysenko menetti lopullisesti hallinnolliset asemansa. Hän oli kuolemaansa asti tiedeakatemian rivijäsen.

Mendel, GreGor (1822-1884).
Varattomuutensa vuoksi augustiinimunkiksi ajautunut kasvinjalostaja, joka osoitti kokeillaan 1860luvulla että ominaisuudet periytyvät kappalemaisten perintötekijöiden ("geenien") välityksellä. Mendelin vuonna 1900 uudelleen löydetyt tulokset muodostavat modernin genetiikan perustan, josta Lysenko sanoutui irti.

MitshuRin, Ivan Vladimirovitsh (1855-1935). Neuvostoliiton maataloustutkimuksen edelläkävijäksi kohotettu hedelmätarhuri, joka aluksi työskenteli rautatievirkamiehenä mutta perusti 1890 -luvulla säästöjensä varassa oman taimitarhan. Mitshurin oli taitava hedelmäpuiden jalostaja ja oksastaja sekä kehitti kokemustensa nojalla periytymistä koskevan vaistonvaraisen teorian, jossa ympäristön vaikutuksella oli suuri osuus. Lysenko poimi Mitshurinin opista aineksia omaan teoriaansa. Lisäksi Mitshurinista muodostui henkilöhistoriansa ansiosta kansan riveistä kasvaneen sosialistisen tiedemiehen malli ("Todenperäisen tieteen luominen tsaarinvallan aikana oli todella urotyö", kertoo Darvinismin perusteet.)

MoRGAN, ThOMAs HunT (18661945). Yhdysvaltalainen geneetikko, joka johti Columbian yliopiston kuuluisaa Drosophila-laboratoriota vuosisadan alussa ja joka tutkimusryhmineen osoitti Mendelin postuloimien perintötekijöiden sijaitsevan kromosomeissa. Lysenko vastusti ankarasti käsitystä perintötekijöiden lokalisoitumisesta.

Weissman, August (18341914). Saksalainen evoluutiotutkija, jonka keskeinen teoreettinen perintö on "ituradan" käsite - so. ajatus, että hedelmöittyneestä sukusolusta täysikasvuisen yksilön sukusoluihin muodostuu organismin kasvusolukoista ("soomasta") täysin erillinen solulinja ("ituplasma"). Näiden keskinäisen vaikutussuhteen Weissmann oletti täysin yksisuuntaiseksi: ituplasma määrää sooman ominaisuudet, mutta soomalla ei ole vaikutusta ituplasmaan. Tämä on ristiriidassa 
sen Lysenkon käsityksen kanssa, että perinnölliset muutokset voivat välittyä organismiin mistä elimestä tahansa, esimerkiksi kasveihin oksastuksen välityksellä.

Mendel, Morgan ja Weissman olivat Lysenkolle vaarallisia harhaoppineita, joita hän toistuvasti mustasi $\mathrm{mm}$. dialektisen materialismin termein.

$$
* * *
$$

Lysenkon valtakausi Neuvostoliiton perinnöllisyystutkimuksessa oli valtava tragedia. Hänen käynnistämiensä vainojen nimekkäin uhri oli Nikolai Vavilov, joka oli saanut peruskoulutuksensa jo ennen vallankumousta Englannissa. Vavilov oli nimitetty Edinburgissa vuonna 1939 pidetyn kansainvälisen geneetikkokonferenssin puheenjohtajaksi; kokous piti alunperin järjestettämän Moskovassa kaksi vuotta aikaisemmin. Vavilov ei saanut matkustuslupaa - hänet pidätettiin seuraavana vuonna ja hän menehtyi vankilassa vuonna 1942. Mikä paradoksaalisinta, Vavilov oli vakaumuksellinen tieteen ja sosialismin liiton edistäjä ja piti nimenomaan tästä syystä parempana jäädä vallankumouksen jälkeen Neuvostoliittoon kuin muuttaa länteen.

Dudintsev kirjoittaa henkilöhistorioista, mutta taka-alalla väikkyvät toki tekijät, jotka tekivät Lysenkon valtakauden mahdolliseksi. Tausta on monipolvinen eikä sitä pohdittaessa ole oikotietä Neuvostoliiton varhaisvuosien historiallisen tilanteen ja siihen liittyneiden valtaisien vaikeuksien ohi.

Neuvostoliiton maatalouden rappio ja maan elintarvikepula 1920-30-luvuilla oli lysenkolaisuuden keskeinen tausta. Syntyi voimakas sosiaalinen tilaus lupauksille saada ravintohuolto nopeasti kuntoon. Lysenko tarttui tähän esittäen mm. "jarovisaation" keinona kohottaa nopeasti maatalouden tuottavuutta, kun taas maataloustieteiden akatemian tutkijat, Vavilov heidän muassaan, rakensivat pitkäjänteisen geneettisen pe- rustutkimuksen ja kasvinjalostuksen varaan.

Perinnöllisyystieteen teoriassa oli 30-luvulla avoimia kysymyksiä, jotka liittyivät erityisesti kasvien perinnöllisyyden mekanismeihin. Näistä Lysenko lähti liikkeelle (tästä erityisesti R. Levins \& R. Lewontin: "The Problem of Lysenkoism", sisältyy kirjaan Dialectical Biologist, Harvard Univ. Press 1985).

Lysenkon tarjoamien lääkkeiden erityinen vetovoima oli siinä, että ne perustuivat viljelijöiden omaan aktiivisuuteen. Niiden toteuttamiseksi järjestettiin kolhoosilaisia mobilisoivia kampanjoita, mikä toi ratkaisuihin välittömän poliittisen ulottuvuuden: Pakkokollektivisoinnin masentamalle maaseudulle piti levittää vaikutelma, että elintarvikehuolto on puolueen hallinnassa ja pula nopeasti korjautumassa.

Lysenko toimi aluksi kaiketi hyväuskoisuuttaan. Hänen koulukuntansa tuloksiin ei tiettävästi sisälly suoranaisia väärennöksiä - joskin koejärjestelyt olivat äärimmäisen epämääräisiä ja niiden tulokset monitulkintaisia (tämän Dudintsev osoittaa hyvin); siksi tuloksia ei pystytty muualla toistamaan eikä niillä ole tieteellistä arvoa. Myöhemmin Lysenkon toimintaan alkoi kuitenkin tulla tietoisempi petoksen maku. Hrushtshevin aikana hän muutti sujuvasti tutkimuksensa painopisteen ongelmasta toiseen, esimerkiksi uudismaiden metsityksestä lypsykarjan jalostukseen, sitä mukaan kun aiemmat lääkkeet osoittautuivat käytännössä tehottomiksi, osin jopa seurauksiltaan katastrofaalisiksi.

Subjektivismi - suuret mutta perusteettomat lupaukset - tässä lysenkolaisuuden yksi ponnin. Tämän muutti vaikuttavaksi voimaksi stalinistisen puoluehallinnon poliittinen ja ideologinen tuki. Lysenkolaisuus yhdistyi Stalinin kulttuurivallankumoukseen, jonka osana luotiin uutta tutkijan (intellektuellin) ihannetta. Tämä oli itseoppinut, kansan riveistä noussut ja kansan etua palveleva puolueen suojatti. Tästä ajatus "kahdesta tieteestä": Maailmanhistorian näyttämölle oman valtionsa johtoon noussut proletariaatti kehitti uudentyyppisen proletaarisen tieteen, joka oli porvarillisen tieteen antiteesi. Mitshurinilais-lysenkolainen biologia soveltui erinomaisesti proletaarisen tieteen illustraatioksi. Sen taustalla oli tsaarin Venäjällä eläneen ja vaikeuksia kokeneen käytännön miehen vaistonvarainen teoria. Sitä kehitti talonpoikaissyntyinen sosialistisen Neuvostoliiton kasvatti. Se piti johtotähtenään kansan polttavien tarpeiden palvelemista.

Erityisesti sodan jälkeen proletaarisen tieteen ideologiseen julistukseen liittyi fobia kaikkea ulkomaalaisuutta kohtaan. Neuvostoliiton on tultava toimeen omilla jaloillaan; tämä pätee myös tieteessä, jossa länsi käyttää kansainvälistä vaihtoa aatteellisen solutuksen välineenä. Neuvostotutkijoiden isänmaallisuus oli koetuksella. Myös tämän ristiriidan Dudintsev on oivallisesti tavoittanut kirjassaan.

Dialektisen materialismin kaavaoppi - Lysenkon toinen ponnin. Omia keskinäisiä taisteluitaan käyvät filosofit tarttuivat lysenkolaisuuteen löytäen siitä todisteet dialektiikan filosofisten periaatteiden ylivertaisuudesta konkreettisen tutkimuksen ohjenuorana. Weismannilais-mendelistis-morganilainen genetiikka oli metafyysistä ja siksi virheellistä; lysenkolaisuus sen sijaan todisti käytännössä dialektiikan lait.

Neuvostoliiton keskittynyt ja hierarkkinen tieteellisen hallinnon järjestelmä - kolmas ponnin. Keskeiset biologian alan tutkimuslaitokset oli mahdollista puhdistaa hallinnollisin toimin, ja julkaisut olivat valvonnassa. Jokin määrä geneettistä tutkimusta pystyi suurin vaikeuksin talvehtimaan syrjäisillä laitoksilla ja paikkakunnilla, mutta tieteellisissä lehdissä esiintyneet yritykset kritikoida julkisesti Lysenkoa johtivat toimituskuntien vaihtumisiin tai lehtien lakkauttamisiin. 
Lysenkolaisuuden ongelma leikkaa syvältä tieteen ja yhteiskunnan suhteen perustavia kysymyksiä. Siksi yksiviivaisen antineuvostoliittolaiset historiikit Lysenkon tapauksesta (esimerkiksi David Joravsky, The Lysenko Affair, Harvard Univ. Press 1970) eivät ole kiinnostavia. On myös liian yksinkertaista esittää Lysenkon tarina tieteellisen huijarin ja byrokraattisen puoluekoneiston salaliittona (Zhores Medvedev, The Rise and Fall of T. D. Lysen$k o$, Columbia Univ. Press 1969). Ongelma kytkeytyy siihen, miten tiedettä ylimalkaan voidaan tietoisesti ohjata ratkaisemaan keskeisiä yhteiskunnallisia ongelmia. Kuka määrittelee ongelmat? Kuka päättää, mistä suunnasta ratkaisuja haetaan? Kuka valvoo, että ratkaisujen tieteellinen perusta kestää? Kuka ennakoi tarjottujen ratkaisujen vaikutuksia muihin ongelmiin? Miten taataan, että kriittiset kysymykset selvitetään ennen kuin pitkälle tulevaisuuteen ulottuvia sitoumuksia tietyn ratkaisulinjan hyväksi tehdään?

Lysenko kehitti tarjoamiensa viljelyteknisten ratkaisujen tueksi koko perinnöllisyystieteen kattavan teorian, ja nujersi tämän alle vaihtoehdot - Stalinin puolueen filosofien, ideologien ja poliitikkojen tuella. Tämän Neuvostoliitossa tapahtuneen prosessin kulttuurihistoriaa kaipaamme kipeästi. Mutta älkäämme antako hämätä itseämme: Lysenko ja lysenkolainen subjektivismi kurkkii olkapäällä aina kun tiedettä vaaditaan ensisijaisesti kehitettäväksi joidenkin käytännöllisten ongelmien ratkaisemisen näkökulmasta.

Tiedettä toki kuitenkin tarvitaan yhteiskunnallisten ongelmien ratkaisuun. Ongelman vaikein ydin on nykypäivää.

$$
* * *
$$

Tärkeä osa lysenkolaisuuden tarinaa on sen ulkomailla herättämä keskustelu. Tapauksella oli 4050 -lukujen vaihteessa valtava vaikutus kommunistisiin puolueisiin ja niiden suhteisiin omaan älymystöönsä (ei kuitenkaan SKP:ssa, jolta tämä suhde puuttui). Puolueet määrittelivät hallintopäätöksin biologisen tutkimuksen oikean ideologisen linjan. Tulilinjalle joutuivat ensi sijassa biologit - Englannissa puolueeseen joutuivat ottamaan pesäeroa mm. John D. Bernal ja J. B. S. Haldane, Ranskassa Marcel Prenant, yksi vastarintaliikkeen tärkeimmistä johtomiehistä. Yhdysvaltalaisista lysenkolaisuuteen törmänneistä biologeista nimekkäin oli H. J. Muller, nobelisti, joka poliittisen vakaumuksensa nojalla työskenteli Moskovassa useita vuosia 30-luvulla, mutta lähti vuonna 1937 - lopullisesti.

Yksi kiinnostavimmista aikalaisdokumenteista on Unescon silloisen pääjohtajan, huomattavan evoluutiobiologin Julian Huxleyn Lysenkosta kirjoittama kirja (Soviet Genetics and World Science. Lysenko and the Meaning of Heredity, Chatto and Windus 1949), jossa hän kritikoi aikansa genetiikan näkökulmasta lysenkolaisuuden kappaleiksi ja esittää yhteenvedon liberalistisista argumenteista stalinistista tiedehallintoa vastaan.

Suomessa lysenkolaisuutta seurattiin, mutta se herätti varsin vähän julkista keskustelua (professori Esko Suomalaisen kertoman mukaan). Lysenkon koulukunnan edustaja Ivan Glushenko kierteli muutaman kerran genetiikan laitoksilla Pohjoismaissa, ja hänen keskustelujensa tuloksena joukko pohjoismaisia professoreita tuli Izvestijassa leimatuksi taantumuksellisen mendeliläis-morganismin kovapäisiksi edustajiksi. Ruotsissa julkinen keskustelu oli vilkkaampaa - yhtenä sen moottorina oli Tukholman genetiikan professori Åke Gustafsson, joka mm. kirjoitti pääsihteeri Hrushtsheville avoimen kirjeen tammikuussa 1958 (jouduttuaan Lysenkon hampaisiin Izvestijassa).

Näiden tarinoiden kaiut ovat edelleen keskuudessamme. Kommunististen puolueiden suhde äly- mystöön sai 40-50-luvun keskusteluissa kolauksia, joiden seurauksia ei ole vielä laisinkaan käsitelty loppuun (hyvä aloitus on Dominique Lecourt, Proletarische Wissenschaft? Der "Fall Lyssenko" und der Lyssenkismus, VSA 1976).

Yleiseen tiedekeskusteluun on jäänyt Lysenkon luuranko, joka symboloi milloin stalinistisia hallintokäytäntöjä, milloin mitä tahansa pyrkimystä korostaa yhteiskunnallisia ongelmia tutkimuksen ohjaamisen perustana. Luuranko lojukoon kaapissaan, mutta tieteen ja käytännön suhde vaatii jatkuvaa kritiikkiä. Lysenkolaisuuden kipeiden taustojen selvittäminen on onnistumisen yksi edellytys.

$$
* * *
$$

Aloitin lainauksella keskikoulun oppikirjasta. Sillä on vielä yksi tarina, jota Dudintsev ei juuri kata, mutta jonka käsittelyyn meilläkään ei ole aineksia.

Väittämä on esitetty keskikoulun oppikirjassa. Se oli opetuksessa hallitsevana parin-kolmen vuosikymmenen ajan. Kaksi-kolme sukupolvea sai sen pohjalta koulutuksensa. Mikä on perintö?

Yrjö Haila 